\title{
Overview of Retained Products of Conception And its Management
}

\author{
Dr. Pavitra Sharma ${ }^{1}$,Dr. Vinu Choudhary ${ }^{2}$,Dr. Priyanka Rahariya ${ }^{3}$ \\ ${ }^{1}$ Assistant Professor, Dept. Of Obs. \& Gynaecology, Sawai Man Singh Medical College, Jaipur, Rajasthan. \\ ${ }^{2}$ Senior Resident,Dept. Of Obs. \& Gynaecology, Sawai Man Singh Medical College, Jaipur, Rajasthan. \\ ${ }^{3}$ Medical Officer,Dept. Of Obs. \& Gynaecology, Sawai Man Singh Medical College, Jaipur, Rajasthan.
}

\begin{abstract}
Introduction: Partial or complete retention of products of conception after delivery or abortion is referred to as "RPOC". RPOCs are suspected whenever a female presents with sustained or prolonged vaginal bleeding after a period of amenorrhea as in cases of spontaneous or induced abortion or following delivery. Besides clinical examination, ultrasound is indispensable for evaluation.

Depending on the patient's general condition, symptoms and size of RPOCs, medical or surgical evacuation is planned. Complications like anemia, sepsis, drug reaction or those inherent to the surgical procedure should be diagnosed timely and appropriately managed.

Methodology: This study was conducted at Mahila Chikitsalaya, S.M.S. medical college, Jaipur over a period of 3 months, from January 2016 to March 2016. 100 women presenting to the OPD with history of amenorrhea followed by bleeding per vaginum, pain abdomen or expulsion of a fleshy mass were clinically examined and ultrasonographically confirmed for RPOCs. These patients were given either medical treatment (T. Misoprostol $600 m c g$ vaginally) or surgical evacuation.

Result: RPOCs were found to be more common in multiparous women and abortion rate decreased with increasing gestation. Medically planned abortions resulted in fewer RPOCs. Medical management was found to be better for smaller sized RPOCs and at lesser gestational age while surgical evacuation was better for larger sized RPOCs occurring at advanced gestation in terms of patient satisfaction, complications and success rate. Complications with both were minimal.
\end{abstract}

\section{Introduction}

Partial or complete retention of products of conception after delivery or abortion is referred to as "RPOC". RPOCs are suspected whenever a female presents with amenorrhea followed by sustained or prolonged vaginal bleeding as in cases of spontaneous or induced abortion orfollowing delivery. Besides clinical examination, ultrasound is indispensable for evaluation. It may present as an endometrial mass/thickening (ET> $10 \mathrm{~mm}$ ) with or without vascularity or echogenic/complex fluid within the endometrial cavity. Depending on the patient's general condition, symptoms and size of RPOCs,medical or surgical evacuation is planned. With the advent of high resolution transvaginal sonography, early pregnancy miscarriages have been reclassified into anembryonic pregnancy, early fetal demise, incomplete miscarriage and complete miscarriage [1-8].

In recent times as a result of positive experiences with prostaglandin analogue (most commonly misoprostol), the medical termination of the first trimester miscarriage is accepted as a safe and effective alternative[5]. However, this method is not without its inherent complications like the need for emergency surgical evacuation, pain, an increase in induction abortion time, and also an increase in the analgesic requirement[3,5]. ]. Surgical, medical and expectant management are the various options available to manage early pregnancy miscarriages; each with its own merits and demerits [3,4].Complications like anemia, sepsis, drug reaction or those inherent to the surgical procedure should be diagnosed timely and appropriately managed.

In the last two decades, the efficacy and safety of expectant management which allows for the spontaneous passage of retained products of conception has been studied and confirmed [4,5]. This prospective study also compares the success rate and complications of early pregnancy miscarriages which were treated by medical management, with surgical uterine evacuation.

\section{Method}

This study was conducted at Mahila Chikitsalaya, S.M.S. medical college, Jaipur over a period of 3 months, from January 2016 to March 2016. 100 women presenting to the OPD with history of amenorrhea followed by bleeding per vaginum, pain abdomen or expulsion of a fleshy mass were clinically examined and ultrasonographically confirmed for RPOCs.These patients were given either medical treatment (T.Misoprostol $600 \mathrm{mcg}$ vaginally) or surgical evacuation depending on the patient's hemodynamic status. 


\section{Inclusion Criteria-}

1. Patient diagnosed with retained products of conception clinically and on ultrasound examination.

2. General condition - fair

3. Blood pressure $120 / 80 \mathrm{mmhg}$.

4. Inclusion Pulse rate- $72 / \mathrm{min}$.

5. Clinically and on ultrasonography not diagnosed as ectopic pregnancy

6. No history of diabetes, asthma, cardiac disease, epilepsy, hypersensitivity to Misoprostol.

7. No signs of sepsis.

8. Patient willing for study.

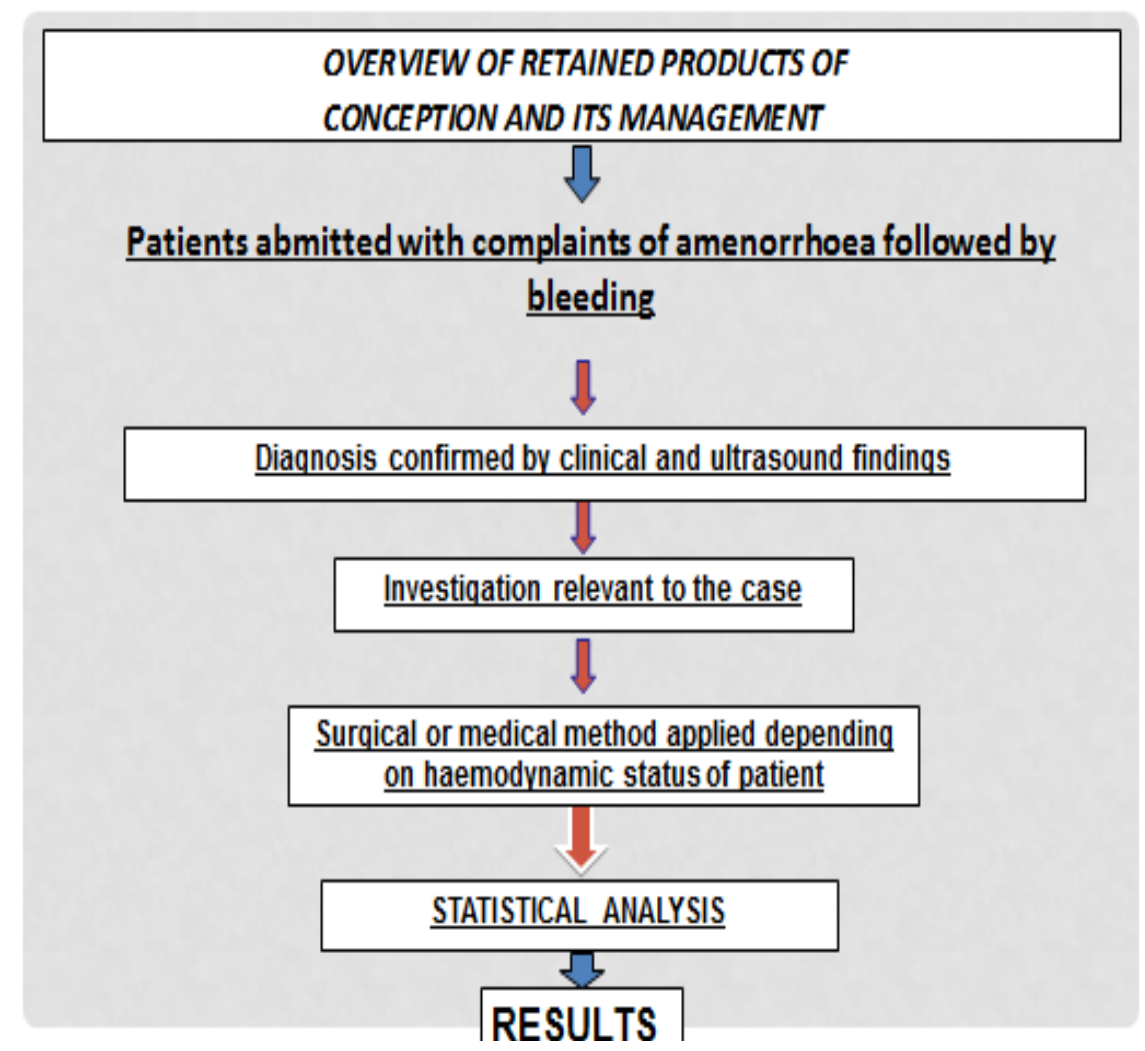

III. Results

In the study it was found that the mean age was 26.16 yrs. Out of the 100 patients studied,32 (32\%) were primigravidae and $68(68 \%)$ were multigravidae of which $48(48 \%)$ had previous vaginal birth, $14(14 \%)$ had caesarean and 6(6\%) had previous abortion.

Table 1:

\begin{tabular}{|ll|}
\hline O/H & $\mathbf{n}=\mathbf{1 0 0}$ \\
\hline Primi & 32 \\
\hline Multi & 68 \\
\hline
\end{tabular}

Table 2:

\begin{tabular}{|lc|}
\hline Previous obstetric history & $\mathbf{n}=\mathbf{6 8}$ \\
\hline Vaginal birth & 48 \\
\hline LSCS & 14 \\
\hline Abortion & 6 \\
\hline
\end{tabular}




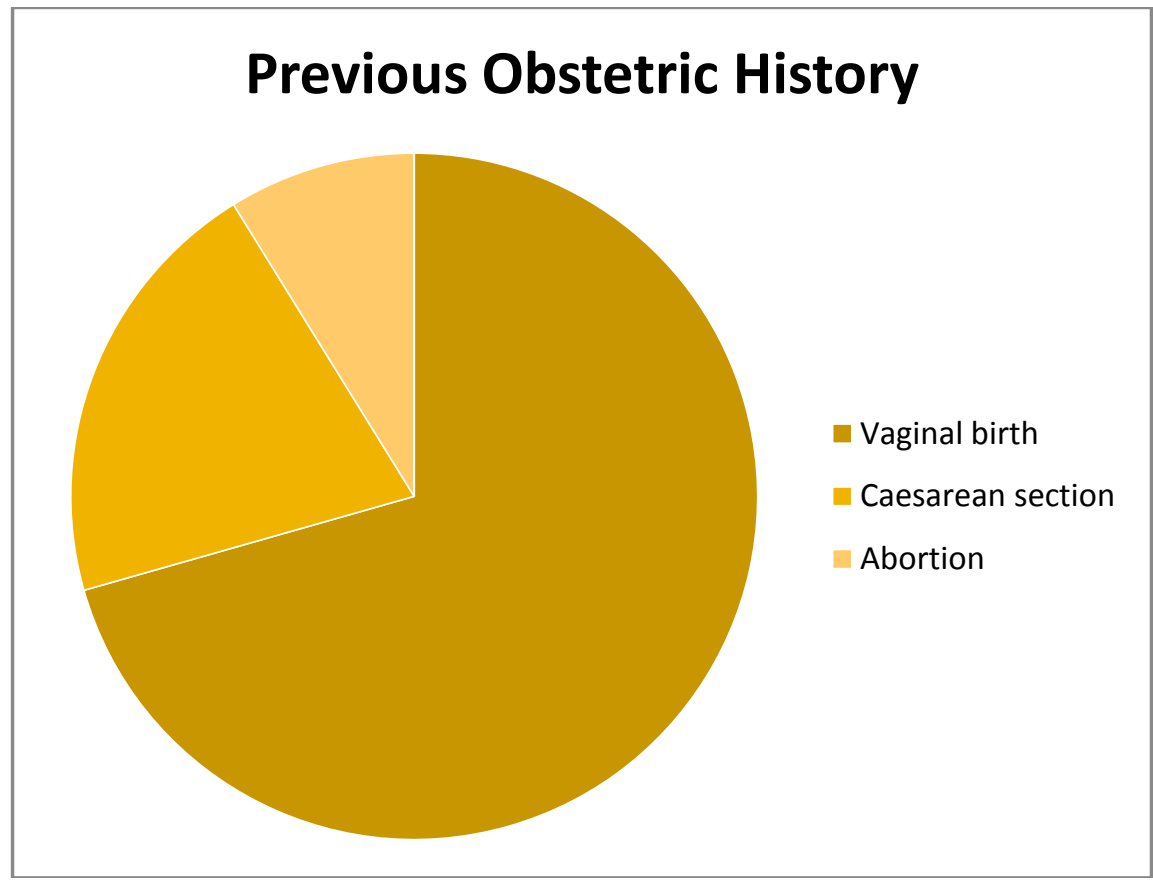

Table 3:

Fifty $(50 \%)$ patients with RPOCs presented with POG $<6 \mathrm{wks}, 32(32 \%)$ presented between $6^{1 / 7}$ to 9 weeks, while $12 \%$ presented with $9^{1 / 7}$ to 12 weeks period of gestation. Only $6 \%$ presented with retained products of conception in $>12^{1 / 7}$ weeks period of gestation.

\begin{tabular}{|l|c|}
\hline Period of Gestation (weeks) & $\mathbf{n}=\mathbf{1 0 0}(\%)$ \\
\hline$<\mathbf{6}$ & $50(50 \%)$ \\
\hline $\mathbf{6}^{1 / 7} \mathbf{- 9}$ & $36(36 \%)$ \\
\hline $\mathbf{9}^{1 / 7} \mathbf{- 1 2}$ & $10(10 \%)$ \\
\hline$>\mathbf{1 2}$ & $04(04 \%)$ \\
\hline
\end{tabular}

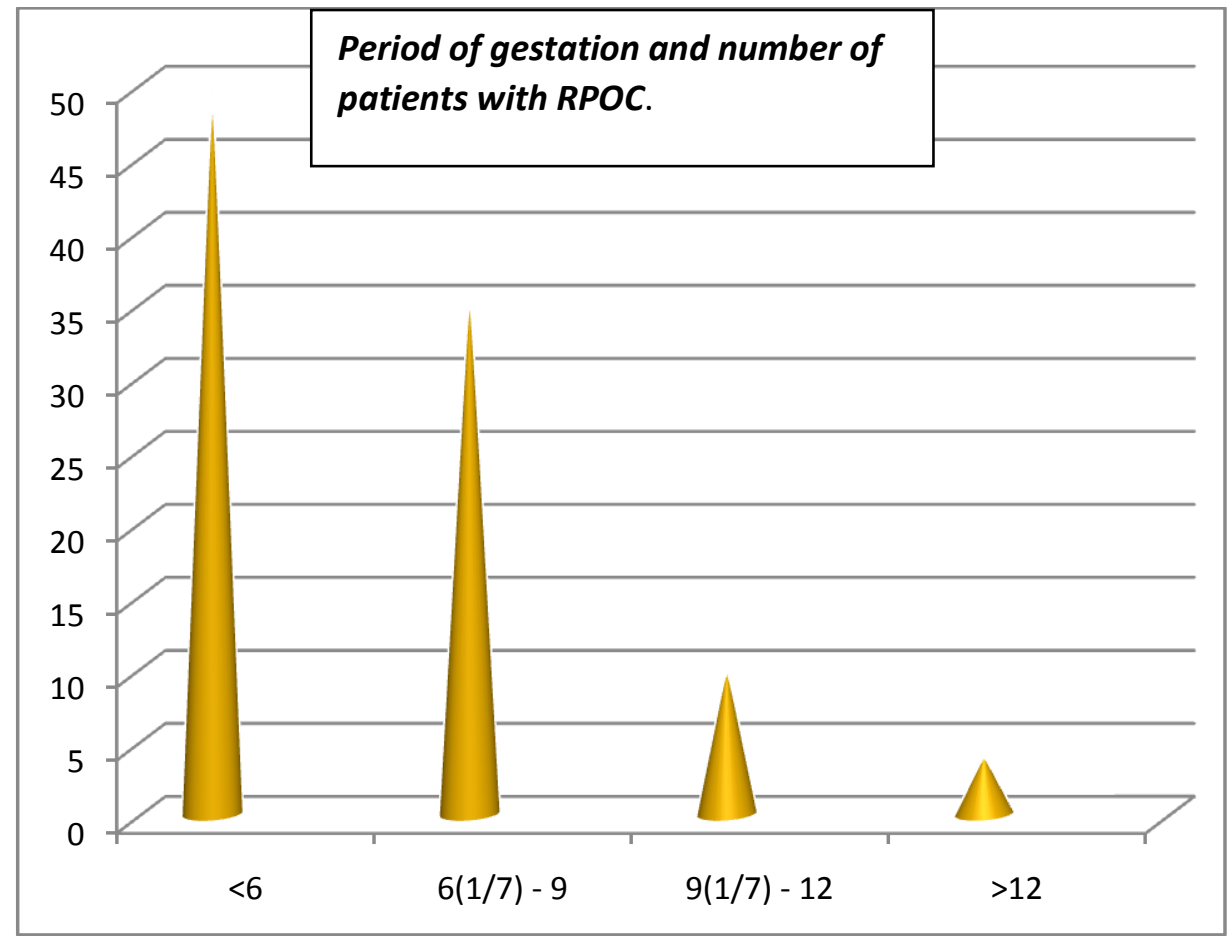

Table 4: 
Seventy four (74\%) patients with spontaneous abortions presented with RPOCs as compared to 26 (26\%) with medical abortions.

\begin{tabular}{|ll|}
\hline Origin of RPOCs & $\mathbf{n = 1 0 0}$ \\
\hline Medical Abortion & 26 \\
\hline Spontaneous Abortion & 74 \\
\hline
\end{tabular}

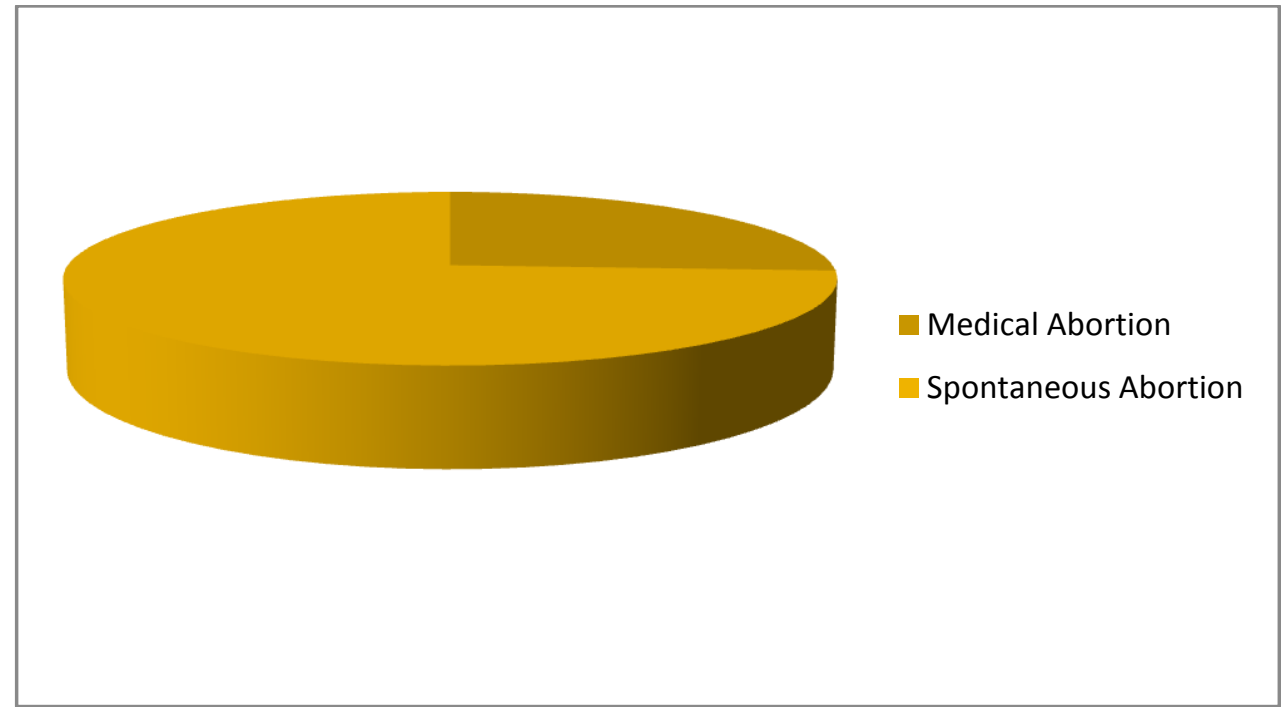

Table 5:

Out of the 100 patients, 34 (34\%) were managed medically with failure of treatment in $10(10 \%)$ while $66(66 \%)$ were managed surgically with failure of treatment in $6(6 \%)$.

\begin{tabular}{|lcc|}
\hline Treatment & $\mathbf{n}=\mathbf{1 0 0}$ & failure $(\mathbf{n}=\mathbf{1 6})$ \\
\hline Medical & 34 & 10 \\
\hline Surgical & 66 & 6 \\
\hline
\end{tabular}

Table 6:

Majority of 44 patients (44\%) presented with RPOCs of size 26-50mm,36 (36\%) patients with 16$25 \mathrm{~mm}$ size, $18(18 \%)$ with $=$ or $<15 \mathrm{~mm}$ while only $2(2 \%)$ presented with $>50 \mathrm{~mm}$ size of RPOCs.

\begin{tabular}{|l|c|}
\hline Size of RPOC $(\mathbf{m m})$ & $\mathbf{n = 1 0 0}$ \\
\hline$<\mathbf{1 5}$ & 18 \\
\hline $\mathbf{1 6 - 2 5}$ & 36 \\
\hline $\mathbf{2 6 - 5 0}$ & 44 \\
\hline$>\mathbf{5 0}$ & 02 \\
\hline
\end{tabular}

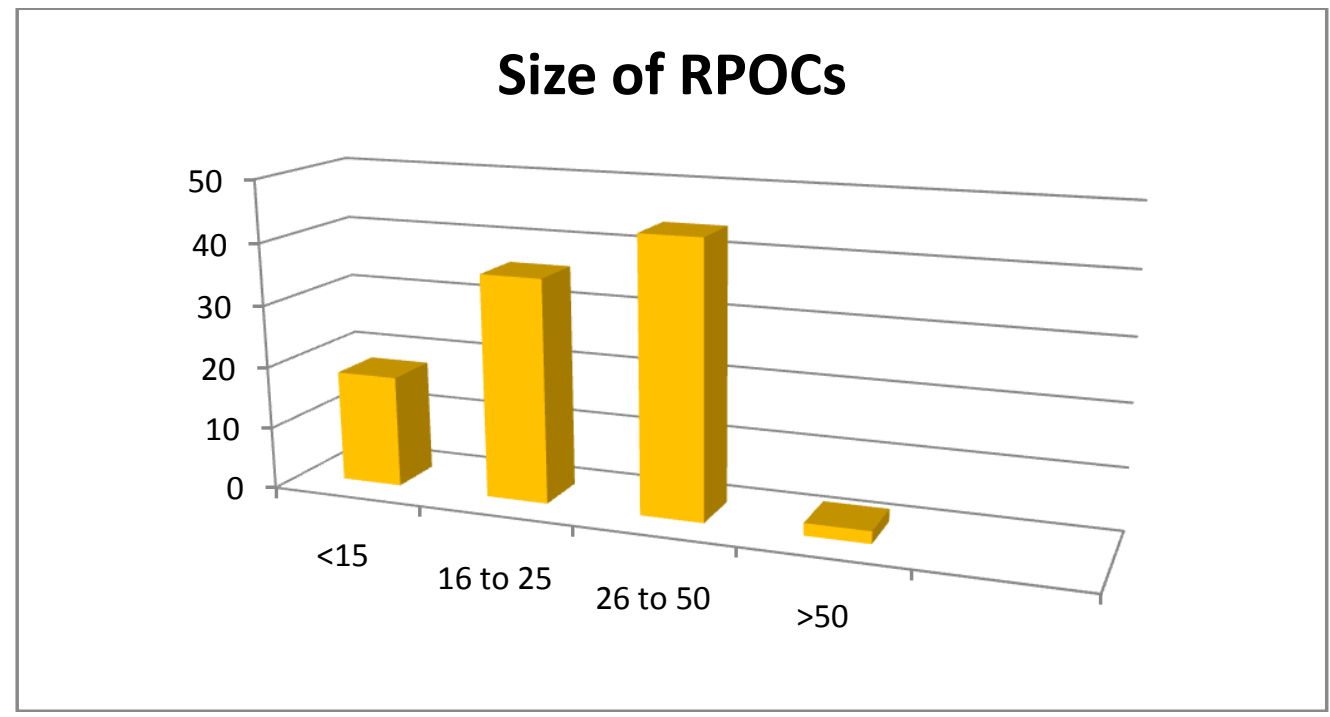

Table 7: 


\section{Distribution table showing co-relation between size of RPOC and type of management:}

It was found that medical management with $600 \mathrm{mcg}$ of T.misoprostol (PgE1) placed vaginally was more efficacious in RPOCs upto $15 \mathrm{~mm}$ while medical and surgical management were equally efficacious for RPOCs upto16-25mm. Surgical management was more successful in RPOCs $26-50 \mathrm{~mm}$ size while only surgical treatment was done for size or RPOCs $>50 \mathrm{~mm}$. This finding was found to be statistically significant using Chisquare test of significance.

Chi-square $=25.940$ with 3 degrees of freedom; $\mathrm{P}=0.000$

\begin{tabular}{|c|c|c|}
\hline Size of RPOC (mm) & Medical & Surgical $\quad$ P Value \\
\hline$<15$ & 12 & 06 \\
\hline 16 to 25 & 18 & 18 \\
\hline 26 to 50 & 04 & 38 \\
\hline$>50$ & - & 04 \\
\hline
\end{tabular}

Table 8:

Distribution table showing co-relation of period of gestation \& type of management:

It was found in the study that medical and surgical management were equally efficacious for RPOCs up to 6 wks of POG whereas surgical management was more efficacious for RPOCs > 6wks. This finding was found to be statistically significant using Chi-square test of significance.

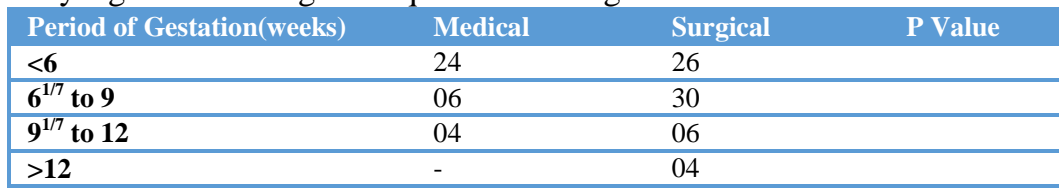

Chi-square $=11.408$ with 3 degrees of freedom; $\mathrm{P}=0.012$

\section{Discussion}

In this study it was found that abortions were more common in multigravidae as compared to primigravidae which is in coherence with the findings of Pollack et al (2009) [9] who found that spontaneous abortion rates increase with gravida status and increasing gravida status could be a significant risk factor. The maximum patients $(50 \%)$ with RPOCs were found with POG $<6$ wks and decreased with increasing gestational age which is consistent with the fact that frequency of abortions decreases with increasing gestational age as supported by Wilcox AJ, Weinberg C.R., O'Connor JF et al [10,11]. RPOCs were more common in spontaneous abortions $(74 \%)$ as compared to medical abortions (36\%).In this study it was concluded that medical management was a more suitable management option forsmaller sized RPOCs in terms of success rate , complications and patient satisfaction whereas with increasing size of RPOCs, surgical management was better when these criteria were considered.There were no differences in serious adverse events between the medical management and surgical treatment groups.

Overall, there were two women in medical management group who required blood transfusion. Sixteenpatients $(16 \%)$ had failure of primary treatment of which $10(10 \%)$ weremanaged medically and 6(6\%) were managed surgically. All of these 16 patients underwent D\&E as secondary management. Medical treatment had a complete abortion rate of $70.58 \%$ while surgical treatment had a complete abortion rate of 90.9\%. A statistically significant correlation was found between size of RPOCs and treatment modality with surgical treatment being better than medical for RPOCs more than $26 \mathrm{~mm}$. A statically significant correlation was also found between POG of abortion and treatment modality. Surgical treatment was found to be better for POG $6^{1 / 7}$ wks and above.

\section{Conclusion}

The medical management of RPOCs has an acceptable success rate with complications comparable with surgical group except for the unplanned admissions and emergency evacuation. The evidence is insufficient to demonstrate the superiority of either medical or surgical management. Success rate of medical management can be improved with much lesser complication by proper patient selection and counselling. s

\section{References}

[1]. Nielsen S, Hahlin M. Expectant management of first trimester spontaneous abortion. The Lancet. 1995;345:84-86.

[2]. Royal College of Radiologists, Royal College of Obstetricians and Gynaecologists. Guidance on Ultrasound Procedures in Early Pregnancy. London: RCR/RCOG; 1995.

[3]. Ankum WM, Wieringa-de Waard M, Bindels PJ. Management of spontaneous miscarriage in the first trimester: an example of putting informed shared decision making into practice. BMJ. 2001;322(7298):1343-46.

[4]. Nanda K, Peloggia A, Grimes D, Lopez L, Nanda G. Expectant care versus surgical treatment for miscarriage. Cochrane Database of Systematic Reviews. 2006;(2):CD003518 
[5]. Trinder J, Brocklehurst P, Porter R, Read M, Vyas S, Smith L. Management of miscarriage: expectant; medical or surgical? Results of a randomised controlled trial (the MIST trial) British Medical Journal. 2006;332(7552):1235-38.

[6]. Casikar I, Bignardi T, Riemke J, Alhamdan D, Condous G. Expectant management of spontaneous first-trimester miscarriage: prospective validation of the '2-week rule' Ultrasound in Obstetrics and Gynaecology. 2010;35(2):223-27.

[7]. Sairam S, Khare M, Michailidis G, Thilaganathan B. The role of ultrasound in the expectant management of early pregnancy loss. Ultrasound Obstet Gynaecol. 2001;17(6):506-09.

[8]. Shelley JM, Healy D, Grover S. A randomised trial of surgical, medical and expectant management of first trimester spontaneous miscarriage. Australian and New Zealand Journal of Obstetrics and Gynaecology. 2005;45:122-27.

[9]. Pollack AZ, Buck LG, M Sundaram, R Lum KJ(2009).Caffeine consumption and miscarriage, a prospective cohort study Fertil. Steril.93(1):304-306.

[10]. Wilcox AJ, Weinberg C.R., O'Connor JF et al. (Incidence of early loss of pregnancy, N.Engl J Med 1988, 319;189).

[11]. Wang X.Chen C,Wang L et al. conception, early pregnancy loss and time to clinical pregnancy: a population based prospective study. Fertil Steril2003;79:577. 